\title{
Ramon Llull, la ciència del seu temps i el raonament diagramàtic*
}

\section{Lola Badia}

\section{El saber enciclopèdic del segle XIII a la "Doctrina pueril»"}

Els tractats, les monografies, les novelles, els poemes, els diàlegs i els proverbis de Llull serveixen per comunicar i difondre el missatge salvador de l'Art, l'eina intellectual que Déu li havia donat i que servia per reforçar la fe dels cristians, per convèncer els infidels de la bona nova de Jesús encarnat i també (aquest és el punt que interessa ara) per ordenar i comprendre millor totes les ciències.

Moltes obres lullianes absorbeixen i reelaboren en mesures $i$ termes diferents un repertori extens de nocions de caràcter enciclopèdic; les més importants són el Llibre de contemplació en Déu (1271), la Doctrina pueril (1274-76), el Fèlix o Llibre de meravelles (1288-89), l'Arbre de ciència (1295-96) i l'Ars generalis ultima (1305-08). L'entrada de materials enciclopèdics en l'obra de Llull s'ha de situar històricament en el marc de la circulació en vulgar del saber per a ús dels laics, que és un tret típic de la vernacularització del saber.' Les primeres

\footnotetext{
* Aquest treball s'ha dut a terme gràcies al suport de projecte de recerca FFI 2014-53050-C 5-1-P del MINECO i de I'SGR 2014-119 de l'AGAUR. Introduccions generals: Fidora \& Rubio (2008) i Badia, Santanach \& Soler (2013). Per a les dades: Llull DB.

1 Sobre aquest concepte, Cifuentes (2006); Alberni, Badia, Cifuentes \& Fidora (2012) i Badia, Santanach \& Soler (2016).
}

manifestacions d'aquest fenomen d'abast europeu són en llatí i remunten a mitjan segle XII, amb obres com el Dragmaticon philosophiæ de Guillem de Conches, mestre de la catedral de Chartres. En aquesta obra, escrita en un llatí força elegant i plena de records de Sèneca i de Ciceró, un mestre dialoga amb un duc sobre diversos aspectes de filosofia natural. És important de remarcar que això s'esdevé abans de la difusió a Occident del corpus aristotèlic, una arribada d'informació filosòfica i científica que va transformar la cultura europea. La traducció catalana del Dragmaticon philosophiæ, datada al segle XIV, recorda molt de prop, a nivell formal i expressiu, alguns fragments del Fèlix i de l'Arbre de ciència (Badia 2002).

Llull produeix, però, la seva obra quan el procés d'assimilació de les traduccions d'Aristòtil (especialment de la Metafísica i el De anima) ja s'ha consolidat en els curricula universitaris de París i d'Oxford des de la segona meitat del segle XII. També és posterior a la redacció de les grans summes escolàstiques, com ara els monumentals Specula de Vicenç de Beauvais (Naturale, Historiale i Doctrinale) o el De rerum proprietatibus de Bartomeu l'Anglès, de mitjan segle XIII. En els medis monàstics $i$ universitaris dels temps de Llull hi ha una àmplia disponibilitat d'informació sobre els reialmes humà, natural i diví, com es pot veure a la Doctrina pueril (vegeu nota 1 i Ruiz Simon 1999). 
La Doctrina pueril és un manual d'educació primària centrat en la formació cristiana. Tanmateix, un deu per cent del seu contingut està dedicat a l'aprenentatge de la ciència. Llull ens hi proporciona el quadre dels coneixements sobre l'home i la natura que considerava bàsics. En primer Iloc, passa revista al trivi (cap. 73): de la gramàtica, la lògica i la retòrica, Llull recomana sobretot la segona. Del quadrivi (cap. 74), interessa sobretot l'astronomia, perquè és «demostrativa ciència, per la qual ha hom coneixença que los cossos celestials han senyoria e operació sobre los cossos terrenals» (DP: 193). La geometria i l'aritmètica serveixen per aprendre a mesurar i a calcular, i la música per lloar Déu. Llull desaconsella l'estudi de la geometria i de l'aritmètica, perquè «arts són que requereixen tota la humana pensa, la qual ha a tractar de amar e contemplar Déu» (DP: 194).

El capítol 77, «De la ciència de natures», descriu els cinc «començaments de natura» i proposa en esquema la teoria dels quatre elements (foc, aire, aigua i terra), ordenats per les relacions de concordança i contrarietat (DP: 199-202). Per ampliar els coneixements suggereix la següent llista d'obres aristotèliques (o pseudo): Metafísica, Física, Del cel, De la generació i de la corrupció, Dels meteors, De l'ànima, Del son i de la vetlla, De la sensació i del sensible, Dels animals, De les plantes i de les herbes (DP: 202-203). Llull està descrivint la formació bàsica que s'adquiria a la facultat d'arts i que constituiia el primer cicle dels estudis universitaris medievals. Al programa del segle XIII hi havia el trivi, el quadrivi i la física aristotèlica. El capítol 78 completa el quadre amb una introducció elemental a la medicina hipocràtico-galènica, inspirada en la Isagoge de Joannici, present a l'Articella, és a dir el primer llibre de text de les facultats de medicina. Ramon exposa el contingut de les set coses naturals (elements, complexions, humors, membres, virtuts, operacions i esperits), de les sis coses no naturals (alenar, fer exercici, menjar i beure, dormir i vetllar, omplir i buidar, i els accidents o passions de l'ànima), i de les tres coses contra natura (malaltia, ocasió de malaltia, accident morbós). Explica les nocions de sanitat i malaltia, tot descrivint una medicina preventiva que inclou consells propis dels regiments de sanitat (DP: 204-210). En aquest sentit el capítol 78 es complementa amb el 91, «De la manera segons la qual hom deu nodrir son fill», que és un petit regiment d'infància. ${ }^{2}$

\section{Les reformulacions del saber enciclopèdic del "Fèlix» i de l'uArbre de ciència»}

La principal innovació de Llull en el tractament del repertori de coneixements bàsics la trobem en el Fèlix o Llibre de meravelles, escrit a París entre 1287 i 1289 i que és, en part, un manual de filosofia per a laics. ${ }^{3}$ En aquesta obra, que no té versió llatina, Llull fa servir els exemples i les semblances per explicar fenòmens naturals a través de metàfores morals, polítiques o teològiques. Es tracta del desenvolupament d'una tècnica analògica que Llull ja havia teoritzat al Llibre de contemplació en Déu.

Aquesta primera gran obra seva, redactada en una prosa catalana harmònica i elegant, va ser escrita abans del descobriment de l'Art, el mètode que Llull obtingué per illuminació a la muntanya de Randa el 1274. Al Llibre de contemplació els fenòmens naturals ajuden a entendre nocions no perceptibles a través dels sentits: les sensualitats, és a dir les coses que els sentits poden percebre, ben ordenades, explica Llull, ajuden a la comprensió de les intellectualitats, és a dir les coses que no es veuen ni es toquen, les del regne de l'esperit i de la divinitat (Rubio 1997 i LCD).

Els exemples del Fèlix contenen materials allegòrics, moltíssimes anècdotes sobre la conducta social de burgesos, cavallers i clergues, situacions de casuística moral individual i nocions de filosofia natural, que gairebé sempre es presenten en connexió amb una realitat parallela teològica 0 moral. Les associacions d'aquesta mena es basen en la noció de semblança, és a dir l'analogia que Llull estableix entre ordres diferents de la realitat. La informació significativa de la semblança lullliana no l'aporta el contingut de les dues unitats que es posen en relació, sinó l'analogia estructural que s'estableix entre totes dues (Gayà 1980 i Pring-

2 DP: 251-259. Llull aprofita narrativament aquest regiment d'infància al capítol 2 del Romanç d'Evast e Blaquerna, REB: 93-95.

3 Vegeu la introducció i les notes a LM; OS II: 9-393 i Pereira (2012). 
Mill 1991). Vegem-ne una mostra. El capítol 31 del llibre $\vee$ del Llibre de meravelles tracta de les plantes. Fèlix observa com un pagès talla un arbre molt bonic: és un acte aparentment gratuït, que desvetlla meravella. El lector aprendrà una mica més avall que el pagès talla l'arbre perquè fa fulles però no lleva fruit: es tracta del motiu evangèlic de l'arbre estèril, que cal tallar i cremar (Mt 3,10 i 7,19). El filòsof que instrueix Fèlix, però, d'entrada no ho explica en aquests termes, sinó que proposa una semblança: la història d'un usurer avar que no fa almoina i d'un pobre que pensa que seria millor que l'usurer morís. Déu fa morir l'usurer i els diners que aquest acumulava beneficien la comunitat. Aquesta anècdota explica per analogia la raó de la tallada de l'arbre i aporta un escreix d'informació moral, ja que també mostra que cal repartir les riqueses injustament acumulades. El que el lector acaba aprenent però, quan ho ha entès del tot, és que la vida i la funció de les plantes i la vida i la funció dels homes obeeixen als mateixos principis. ${ }^{4}$

Llull va formular la funció pedagògica de l'analogia entre la realitat divina, física i moral als Començaments de medicina (1274-76), donant un sentit especial al terme metàfora. Com pot ser, es pregunta el lector, que es parli de la trinitat i de l'encarnació o dels principis del dret en una obra que descriu les bases de la ciència dels

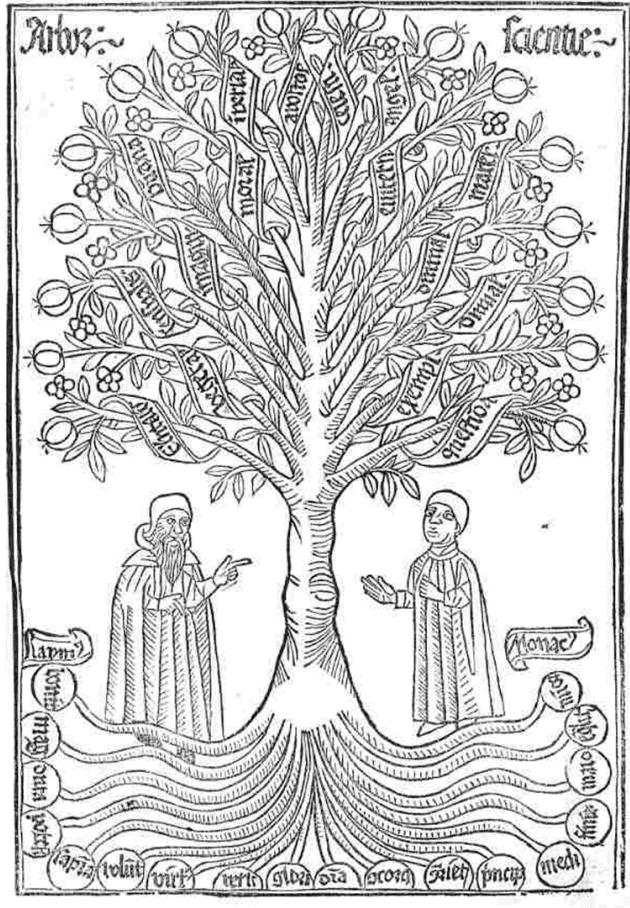

Gravat de l'edició de l'Arbre de ciència (Barcelona, Pere Posa 1505). Ramon i el monjo que dialoga amb ell són al peu de l'arbre simbòlic que representa els catorze arbres de contingut científic i els dos d'instrumentals. Tots setze tenen les mateixes arrels, que són els divuit principis de les Figures $\mathrm{A}$ i $\mathrm{T}$ de les Arts lul-lianes de la segona fase. de les seves competències específiques (Gisbert 2004).

El Llibre de meravelles és la versió en forma d'enciclopèdia per a laics de l'Art demostrativa, la primera formulació completa del mètode general lullià per a totes les ciències i tots els sabers. Els exemples del Llibre de meravelles estan pensats per fer arribar a un públic no acadèmic els coneixements que porten l'home a la salvació: el marc narratiu, les meravelles i les semblances, és a dir els aspectes literaris, són un esquer per atreure el lector perquè aprengui a pujar més amunt de les dades sensibles, cap a les intellectuals. ${ }^{5}$

L'Arbre de ciència és un arbre d'arbres tal com el representa el gravat de l'edició de Pere Posa de 1515. L'Arbre de ciència és el més elaborat dels repertoris de coneixements bàsics lullians: es planteja d'entrada com una nova enciclopèdia, en el sentit que Llull dóna a l'adjectiu nou quan l'aplica a les reformulacions que ofereix per a les diverses ciències $\mathrm{i}$ activitats humanes, de la lògica a l'astronomia passant per la literatura. I és que l'Arbre de ciència és una versió d'accés fàcil de l'Art de Llull, tal com l'havia reelaborada a partir de 1290 en la versió de quatre figures i divuit principis que culmina en l'Ars generalis ultima (1305-08). La versió de referència és la Taula general, de 1293-94. ${ }^{6}$

L'Arbre de ciència desplega catorze arbres temàtics (elemental, vegetal, sensual, imaginal, humanal, moral, imperial, apostolical, celestial, angelical, eviternal, maternal, cristinal, divinal) i dos d'instrumentals (exemplifical i qüestional). Les arrels de l'arbre

5 Vegeu les notes de l'edició del LM de l'editorial Barcino.

6 Per a la periodització de les Arts lullianes, OS I: 55-71 i Badia, Santanach \& Soler (2013: 385-389). Per a l'estructura artística de l'AC, Bonner (2002). 
d'arbres corresponen a les de tots els setze altres arbres que constitueixen l'obra, mentre que els cartells de les branques porten els noms dels arbres temàtics. Tots els arbres tenen set parts, de manera que tots s'organitzen d'una manera homòloga: arrels, tronc, branques, rams, fulles, flors i fruits. Els catorze arbres de contingut corresponen a l'escala dels subjectes de les Arts lullianes de la segona fase i Llull els organitza fent servir els conceptes de les sis columnes de l'alfabet d'aquestes Arts de la segona fase, com ara el de l'Art breu. L'estructura organitzativa de l'Arbre de ciència és una aportació de Llull a la construcció d'un saber universal únic que va ser molt apreciada als temps del Renaixement i del Barroc (Badia 2002).

\begin{tabular}{l|l}
\hline 1. Elemental (I) & \\
\hline 2. Vegetal (H) & \\
\hline 3. Sensual (G) & \\
\hline 4. Imaginal (F) & \\
\hline 5. Humanal (C) & \\
\hline 6. Moral (K) & \\
\hline & 7. Imperial \\
\hline & 8. Apostolical \\
\hline 9. Celestial (D) & \\
\hline 10. Angelical (C) & 11. Eviternal \\
\hline & 12. Maternal \\
\hline & 13. Cristianal \\
\hline 14. Divinal (B) & \\
\hline & 15. Exemplifical \\
\hline & 16. Qüestional \\
\hline &
\end{tabular}

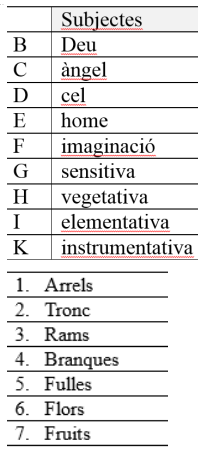

Correlació entre els 14 arbres de l'Arbre de ciència i l'escala de les criatures segons l'alfabet de l'Art breu; i estructura homòloga dels 14 arbres de contingut de l'Arbre de ciència.

Els dos arbres instrumentals de l'Arbre de ciència són l'«Arbre exemplifical» o «Arbre dels exemples» i l'«Arbre qüestional» O «Arbre de les preguntes/qüestions». L'«Arbre exemplifical» proporciona matèria primera per a la predicació, a través del que Pring-Mill (1991) va descriure com la «transmutació de la ciència en literatura». L'«Arbre qüestional», a més de presentar una clara finalitat didàctica — repassar els continguts-, conté explicacions per semblança del mateix tipus de les que es llegeixen al Llibre de meravelles. L'esforç de sistematizació del saber a l'Arbre de ciència descansa sobre la natura homòloga de l'estructura arbòria i descarta el designi de catalogar totes les dades, propi de les enciclopèdies convencionals, acumulant informació de detall: Llull no explica què són les coses, sinó qui- nes són les relacions entre les coses integrades en una concepció global del coneixement.

Vista des de fora, la informació sobre filosofia natural i moral que proporcionen el Fèlix i l'Arbre de ciència és fragmentària i parcial, però Llull la considera suficient. Al Llibre de meravelles havia proposat d'expandir-la amb les semblances. A l'Arbre de ciència ho fa amb els recontaments o narracions breus i els proverbis de l'«Arbre exemplifical» i amb les 4000 qüestions de l'«Arbre qüestional»». Sens dubte el lector del segle $X X \mid$ es troba més desorientat per comprendre els textos enciclopèdics de Llull que no pas els seus coetanis: el repertori de saber aristotèlic mencionat a la Doctrina pueril formava part d'un patrimoni de referència comú avui superat i oblidat.

\section{L'uArs generalis ultima», les Cent Formes i la geometria}

L'Ars generalis ultima (1305-08) és el punt d'arribada definitiu del sistema d'ordenació del saber de Ramon. L'Art breu (1308) n'és la versió resumida, la versió manual o de butxaca. El capítol 10 de totes dues obres conté una aplicació de l'Art a les Cent Formes, és a dir cent nocions generalíssimes que ja havien estat investigades en altres bandes; per exemple, al final dels arbres elemental i sensual de l'Arbre de ciència i també a la Logica nova (1303)? Les llistes de les Cent Formes difereixen d'una obra a l'altra, tot i que sempre tenen la mateixa funció: ensenyar a descobrir la veritat de les idees generals a través dels mecanismes de l'Art.

A l'Ars generalis ultima i a l'Art breu Llull aplica l'Art, en primer $\|$ oc, a 79 nocions abstractes (com ara entitat, essència, unitat, pluralitat, natura...) i després a les que Llull anomena «arts generals» i «arts particulars». Hi retrobem el repertori de les disciplines de la Doctrina pueril: teologia, filosofia, les disciplines del quadrivi i del trivi, el dret i la medicina. En la versió extensa de l'Ars generalis ultima, Llull alguns cops ofereix una riquesa de precisions sobre la seva manera d'entendre determinades qüestions que no dóna en cap altre Iloc, com és el cas de la retòrica, la

7 Bonner \& Ripoll (2002: 20-22) i Bonner (2012: 184-190). 


\begin{tabular}{|c|c|}
\hline 1 Entitat & 51 Derivació \\
\hline 2 Essencia & 52 Ombra \\
\hline 3 Unitat & 53 Mirall \\
\hline 4 Pluralitat & 54 Color \\
\hline 5 Natura & 55 Proporció \\
\hline 6 Gènere & 56 Disposició \\
\hline 7 Espècie & 57 Creació \\
\hline 8 Individualitat & 58 Predestinació \\
\hline 9 Propietat & 59 Misericòrdia \\
\hline 10 Simplicitat & 60 Necessitat \\
\hline 11 Composició & 61 Fortuna \\
\hline 12 Forma & 62 Ordinació \\
\hline 13 Matèria & 63 Consell \\
\hline 14 Substància & 64 Gràcia \\
\hline 15 Accident & 65 Perfecció \\
\hline 16 Quantitat & 66 Declaració \\
\hline 17 Qualitat & 67 Transubstanciació \\
\hline 18 Relació & 68 Alteració \\
\hline 19 Acció & 69 Infinitat \\
\hline 20 Passió & 70 Decepció \\
\hline 21 Hàbit & 71 Honor \\
\hline 22 Situs & 72 Capacitat \\
\hline 23 Temps & 73 Existencia \\
\hline $24 \mathrm{Lloc}$ & 74 Comprehensió \\
\hline 25 Motus & 75 Invenció \\
\hline 26 Immobilitat & 76 Semblança \\
\hline 27 Instinct & 77 Antecedent \\
\hline 28 Apetit & 78 Potència \\
\hline 29 Atracció & 79 Generació \\
\hline 30 Recepció & 80 Teologia \\
\hline 31 Fantasia & 81 Filosofia \\
\hline 32 Plenitud & 82 Geometria \\
\hline 33 Difusió & 83 Astronomia \\
\hline 34 Digestió & 84 Aritmètica \\
\hline 35 Expulsió & 85 Música \\
\hline 36 Significació & 86 Retòrica \\
\hline 37 Pulcritud & 87 Lògica \\
\hline 38 Novitat & 88 Gramàtica \\
\hline 39 Idea & 89 Moralitat \\
\hline 40 Matemàtica & 90 Politica \\
\hline 41 Ens & 91 Dret \\
\hline 42 Punctuitat & 93 Regiment \\
\hline 43 Linea & 94 Cavalleria \\
\hline 44 Triangle & 95 Mercaderia \\
\hline 45 Quadrangle & 96 Navegació \\
\hline 46 Cercle & 97 Consciència \\
\hline $47 \operatorname{Cos}$ & 98 Preïcació \\
\hline 48 Figura & 99 Oració \\
\hline 49 Generals rectituds & 100 Memòria \\
\hline
\end{tabular}

Llista de les Cent Formes de l'Ars generalis ultima / Ars brevis.

gramàtica i la música. ${ }^{8}$ Entre les arts particulars, alienes al currículum universitari, Llull esmenta la política (forma 90), que és l'art amb la qual els burgesos procuren el bé comú, i el regiment, és a dir «la forma amb la qual el príncep regeix el seu poble» (forma 93) (AB: 580). La forma 40 correspon a la matemàtica, també dita metafísica, «la forma amb la qual l'enteniment humà denuda o despulla la substància dels accidents») (AB: 576). És una accepció del terme de caràcter ontològic que té una funció en l'estructura de l'Art, com explica Bonner (2012: 193). També mereixen un tractament específic la milícia (forma 94), l'art de mercadejar (forma 95) i l'art de navegar (forma 96).

En aquesta darrera aplicació Llull calcula la desviació del rumb d'una nau que, sortint d'un port situat al nord, vol anar cap a l'est però ha recorregut quatre milles desviant-se cap a eixaloc (sud-est). Quantes milles hauria recorregut si no

8 Vegeu l'edició catalana de la RN, Pistolesi (2013) i Vicens (2015).

\section{Càlcul de la desviació del rumb d'una nau}

«[...] nauis, uolens ire per orientem; sed uadit per exaloch. Et cum navis iuerit per quattuor miliaria, ipsa quattuor miliaria causant tria miliaria (3 milles) penes orientem. Et quando navis iuerit per octo miliaria apud exaloch, ipsa octo causant sex miliaria apud orientem; et sic multiplicando usque ad centum. Centum quidem causarent septuaginta et quinque uersus orientem» (Ars generalis ultima, ROL XIV, 380, '[...] una nau que vol anar cap a orient; però va cap a eixaloc. Quan la nau hagués recorregut quatre milles, aquestes quatre milles haurien estat tres milles en direcció orient. I quan la nau hagués recorregut vuit milles vers eixaloc, n'hauria fetes sis cap a orient; i repetint el càlcul fina a cent. Cent milles en donarien setanta-cinc cap a orient').

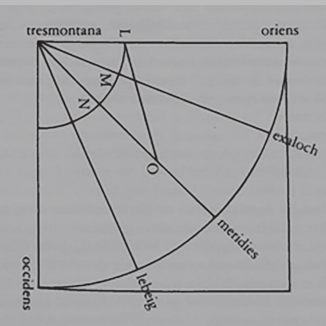

El càlcul suposa que l'angle de desviació cap a eixaloc és de $45^{\circ}$ (se situa a la línia «meridies») de manera que es pot resoldre un triangle rectangle isòsceles. La proporció 4-3 : 8-6: 100-7 és indicativa per experientiam, «empíricament», perquè calculant amb el teorema de Pitàgores la desviació de quatre milles correspon a la hipotenusa, i Llull pregunta per la longitud del catet, que val l'arrel quadrada del quadrat de la hipotenusa dividit per dos, és a dir $\sqrt{ } 8$ i no 3 .

s'hagués desviat? Llull en proposa 3, com els mariners, que ho calculaven a ull, «per experientiam». Llull amplia la relació proporcional de 4 a 3 , a la de 8 a 6 i a la de 100 a 75 (AGU: 380; Badia 2004: 432; Bonner \& Bujosa 2006: 93). El desviament que dóna la imatge que acompanya l'Ars generalis ultima és de $45^{\circ}$ : el que cal resoldre és el càlcul del catet d'un triangle rectangle isòsceles donada la hipotenusa, que és 4. La solució correcta és $\sqrt{8}$ 
i no 3. Decepció davant dels coneixements geomètrics més elementals de Llull?

L'ús que Llull feia de la geometria no correspon a les expectatives dels lectors del segle XXI ni, per descomptat, a les dels historiadors de les ciències exactes. Les figures geomètriques eren un llenguatge imatjat d'un extraordinari potencial significatiu. Llull ho explora a la Geometria nova, escrita a París el 1299, on fa un ús simbòlic dels cercles, els quadrangles i els triangles, que parlen a la ment del lector de realitats superiors com Déu, la natura i l'ànima humana. En la mateixa estada a París Llull va tornar a usar el llenguatge de les figures geomètriques als Principia philosophiæ / Començaments de filosofia i al De quadratura et triangulatura circuli. Llull està interessat pel valor simbòlic de l'equivalència de les àrees del quadrat i del cercle, i també del triangle, més enllà del problema concret - discutit des de l'antigor — de la impossibilitat de dibuixar la figura d'un cercle i d'un quadrat de la mateixa àrea amb regle i compàs. La solució teòrica lulliana del problema recorda la de les lúnules d'Hipòcrates, que a l'Edat Mitjana es llegia al comentari de Simplici a la Física d'Aristòtil.9 Llull proposa una comprovació visual de l'equivalència a partir de la

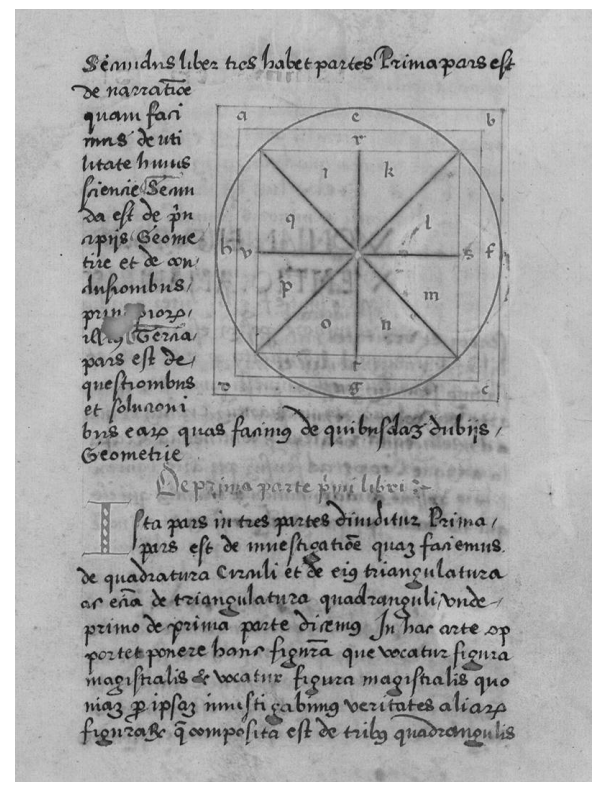

Figura magistral o Figura de la quadratura del cercle, segons el manuscrit 1036 de la Biblioteca Pública de Palma.

9 Badia (2000) i Badia (2004: 427-430). imatge d'un quadrat i un cercle equidistant entre el quadrat inscrit i el circumscrit al mateix cercle.

Com veurem al darrer apartat, les figures de l'Art adquireixen formes geomètriques (cercles, quadrangles, taules) però responen a un plantejament teòric totalment original de Llull, que és el raonament diagramàtic. Llull absorveix dins de la seva Art la geometria i l'aritmètica convencionals del currículum universitari: l'Art les reinterpreta $i$ les reformula en fases successives $i$ en fa disciplines noves, útils per exercitar la intelligència de l'usuari en la direcció correcta que assenyala la nova sistematització. ${ }^{10} \mathrm{~A}$ part dels usos simbòlics que proporciona la geometria, les disciplines del saber enciclopèdic del segle XIII que van interessar més Llull són la medicina i l'astronomia.

\section{Les monografies sobre medicina i astronomia}

Llull va escriure quatre monografies sobre medicina que entronquen amb fases successives de la seva Art: els Començaments de medicina (1274-78), l'Ars compendiosa medicinæ (1285-87), el De levitate et ponderositate elementorum (Nàpols, 1294) i el Liber de regionibus sanitatis et infirmitatis (Montpeller, 1303)." Les obres de Llull sobre la ciència de la salut no constitueixen un corpus autònom amb una projecció, diguem-ne, clínica. Ramon no parla, en efecte, de guarir pacients, sinó de reduir els principis de la teoria mèdica heretada (Hipòcrates, Galè, Avicenna, Averrois, Rhazes, al-Kindi) a una sistemàtica matematitzable, que faciliti els diagnòstics i la confecció de medicaments compostos. Vegem com ho fa als Començaments de medicina. L'obra exposa en deu capítols els principis de la medicina universitària i els de l'Ars compendiosa inveniendi veritatem d'acord amb una figura en forma d'un arbre de tres branques.' $\mathrm{A}$ les arrels de la Figura de la medicina hi ha quatre taules inscrites en un cercle que mostren com es mesclen els quatre humors (còlera, melancolia, sang, flegma), que Llull designa amb les lletres $A B C D$. La branca que surt de l'esquerra repre-

10 OS I: 55-71 i Ruiz Simon (1999).

11 Vegeu les edicions corresponents, Badia (2004: 420425) i Bonner \& Bujosa (2006: 83-85).

12 Vegeu l'edició dels CM, OS II, 395-496, Bonner \& Soler (2015). 
senta els principis de la medicina convencional tal com la descriu la Doctrina pueril. La branca de la dreta és una versió reduïda de l'Art: tres triangles de la figura $T$, més un dels quadrats de la figura $X$.

La branca central representa la relació entre les quatre qualitats elementals (calor, secor, humitat, fredor, també representades per $A B C D)$ i els seus possibles quatre graus d'intensitat. Setze Iletres més de l'alfabet, de la E a la Y, designen aquests quatre graus d'intensitat de cada una de les quatre qualitats. Llull proposava de solucionar per un procediment matemàtic un problema que tenien els metges dels segles XIII i XIV. Els compiladors àrabs havien transmès a l'Occident cristià diverses interpretacions de la teoria galènica dels graus de presència de les qualitats dels quatre elements en les herbes i altres elements anomenats simples que servien per preparar els medicaments compostos; aquestes interpretacions eren objecte de debat a les universitats. Concretament a Montpeller Arnau de Vilanova va ser l'autor d'uns Aphorismi de gradibus (1308) que semblen respondre a un substrat de discussions comú a la solució creativa que proposa Llull.13

Llull estableix que només hi ha setze possibles tipus de me-

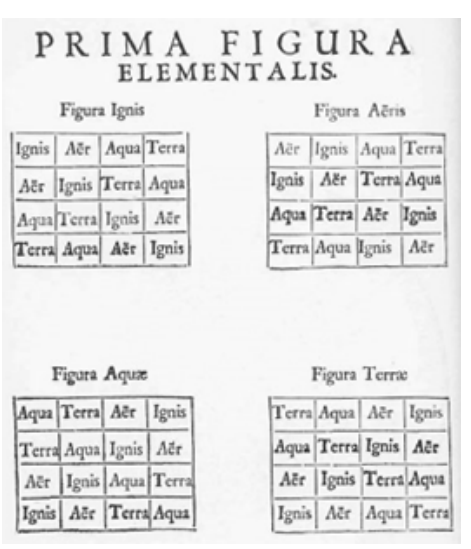

Figura elemental de l'Art demostrativa.

13 Pereira (1979) i Vernet \& Parés (2004: 363-370). Els Aphorismi de gradibus van ser publicats el 1975 a les AVOMO.

14 Bonner \& Soler (2015: 18-21). Vegeu l'apartat següent.

dicaments simples, els designats per les lletres de la E a la Y, la graduació dels quals es presenta en una progressió aritmètica descendent de raó 1: 4, 3, 2, 1; 3, 2, 1; 2, $1 \circ 1$, aplicant successivament la qualitat pròpia $A$, $B, C \circ D$. El pebre és $E$ (4 de foc, 3 de terra, 2 d'aire, 1 d'aigua); la càmfora és $S$ (4 d'aigua, 3 d'aire, 2 de terra i 1 de foc). La representació gràfica d'aquesta solució a les edicions modernes, elaborada ad hoc, es presenta com una taula que també inclou en forma de punts les fraccions d'intensitat dels graus.

Darrerament Anthony Bonner ha descobert que la Figura Elemental de l'Art demostrativa és la traducció diagramàtica del quadre de les qualitats i els graus d'intensitat elaborada per Llull als Començaments de medicina. Al darrere dels quatre quadrats que representen les figures dels graus dels quatre elements de la Figura Elemental s'hi amaga la intuïció d'un reticle (en anglès lattice) resolt en forma d'hipergraf relacional. Els hipergrafs i els reticles són conceptes matemàtics que no han estat formulats fins al segle $X X$. $^{14}$

La intuïció del mecanisme de funcionament dels reticles matemàtics va permetre a Llull de gestionar les relacions de dominància entre les agrupacions d'elements que po- 
sava en contacte. La teoria dels reticles, en efecte, estudia les relacions entre parelles d'elements tenint en compte quin és el superior i quin l'inferior. La innovació metodològica que Llull proposa als Començaments de medicina és el mecanisme que anomena «venciment» en català i devictio en llatí. La seva taula de les setze possibilitats jerarquitzades permet calcular quines qualitats elementals predominen en qualsevol mescla de components simples: sumant els graus de cada una de les qualitats implicades es poden calcular els graus de les diverses qualitats dels compostos per tal d'elaborar correctament els fàrmacs.

El 1297 Llull era a París, on, entre altres obres, va escriure un Tractat d'astronomia.15 En aquesta data la versió de referència de l'Art era la Taula general, una obra de la segona fase o fase ternària de l'Art que deixa de banda la Figura Elemental, però la troballa del venciment es manté. En astronomia el venciment serveix per interpretar les conjuncions dels astres entre ells i amb els signes zodiacals jugant amb la composició elemental dels uns i dels altres. El venciment astrològic lullià facilita la construcció i la interpretació dels horòscops, que era l'objectiu pràctic fonamental de l'astronomia medieval.

Cal tenir present que astronomia i astrologia a l'Edat Mitjana eren indissociables i que el càlcul de les posicions dels astres, és a dir dels planetes en relació als signes del zodíac en cada moment de l'any i en cada zona de la terra, constituïa una de les grans aportacions de la ciència primer àrab i més tard també llatina al desenvolupament del saber matemàtic. ${ }^{16}$ Per calcular un horòscop calia fer servir taules de la situació dels astres i produir-les requeria experts, temps i inversió. Són una fita les taules d'Alfons $X$ de Castella, calculades a Toledo per als anys 1263-1272, l'Almanac que Guillaume de Saint Cloud va elaborar a París el 1292 o les taules que va manar fer Pere III d'Aragó al segle $X I{ }^{17}$

15 N'hi ha una versió catalana antiga, vegeu l'edició del TA. 16 Vegeu-ne més detalls a Vernet \& Parés (2004: 251325).

17 Per a més informació Vernet i Parés (2004: 483-514), i Pereira (1976: 196-199) per a la redacció del TA a París el 1297 i la publicació de l'Almanac el 1292.
El venciment lullià és un procediment fàcil i econòmic, que pot donar un cop de mà als qui no poden dedicar-se a un estudi massa llarg o costós. Al Tractat d'astronomia la descripció dels dotze signes i dels set planetes, amb les característiques de la tradició ptolemaica de transmissió àrab, es complementa amb la dels principis de l'Art, presos de la Taula general. La discussió de cada un dels principis de la Taula general aplicats als planetes i al zodíac obre la porta dels secrets astronòmics, és a dir, de les influències que causen els fenòmens naturals com les estacions de l'any o les malalties de les diferents parts del cos. Atenció: els astres no influeixen la voluntat, altrament l'home no seria lliure de triar entre el bé i el mal.

L'aportació teòrica de Llull a l'astronomia té dos vessants: el sistemàtic i el pràctic. En aquest darrer sector és on esmenta tot passant les taules de les posicions dels astres. Ho fa sense cap èmfasi especial, com parlant d'un material d'ús, donat, accessible. ${ }^{18}$ El desinterès per les taules astronòmiques contrasta amb l'esment de l'astrolabi a la Doctrina pueril, presentat com una eina per mesurar el temps a través de la projecció de l'ombra del sol, i sobretot amb la descripció de l'esfera de la nit o nocturlabi, que és un aparell documentat a Europa des del segle $\times$ (Badia 2004: 430-432 i Bonner \& Bujosa 2006: 91). El tercer aparell de mesura esmentat per Llull, també a la Doctrina pueril, és el quadrant, del qual es diu que serveix per calcular l'alçada d'una torre: Llull proposa un problema de mesura altimètrica d'interès militar documentat en textos de geometria pràctica medievals (Badia 2004: 430-432).

\section{Ramon Llull i el raonament diagramàtic}

És un lloc comú de les presentacions de Llull i del lullisme citar la influència de l'Art de Llull en el

\footnotetext{
18 «E de la segona part d'astronomia no cal tractar, car aquella se pertany als llocs de les hores e los graus, con la planeta o planetes està en lo signe, e aiçò és conegut per l'astalabri e la taula, car ab l'astalabre se prenen les hores per ombra e ab la taula se compten del dia que fo començat lo nombre tro a cert temps. E per aiçò, en quant aquest tractat, suficientment havem parlat d'ell, $e$ de la segona part no cal dir altres raons, mes sotsposar que la taula sia vera», TA: $271 / 371$.
} 


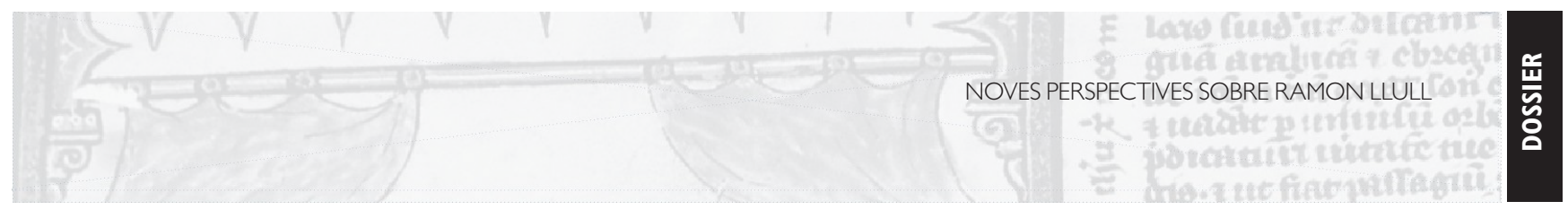

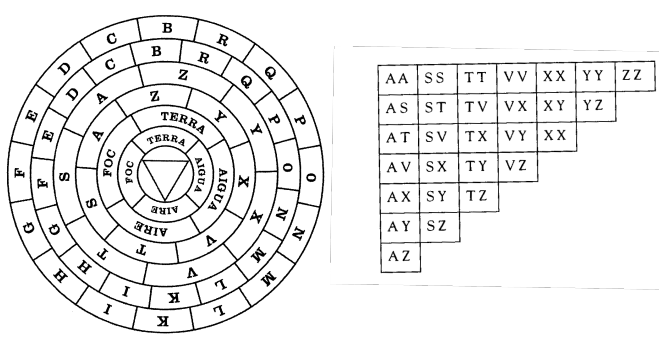

Representació de la Figura Demostrativa acompanyada de la segona figura demostrativa estàndard de l'Ars Demonstrativa, que correspon als cercles 3 i 4 de la figura primera.

càlcul combinatori que Gottfried Wilhelm Leibniz va formular per primer cop. A la seva Dissertatio de arte combinatòria de 1666, el fundador d'aquest filó de les matemàtiques reconeix que l'Art és un precedent de la seva troballa perquè va saber calcular el nombre de combinacions possibles a partir d'uns elements donats amb mitjans gràfics enginyosos i eficaços (Carreras 2001: II, 313-322 i Maróstica 1992). A les Arts de la primera fase, dita quaternària, Llull proposa representacions tabulars de les figures circulars, anomenades «primeres figures»: són les
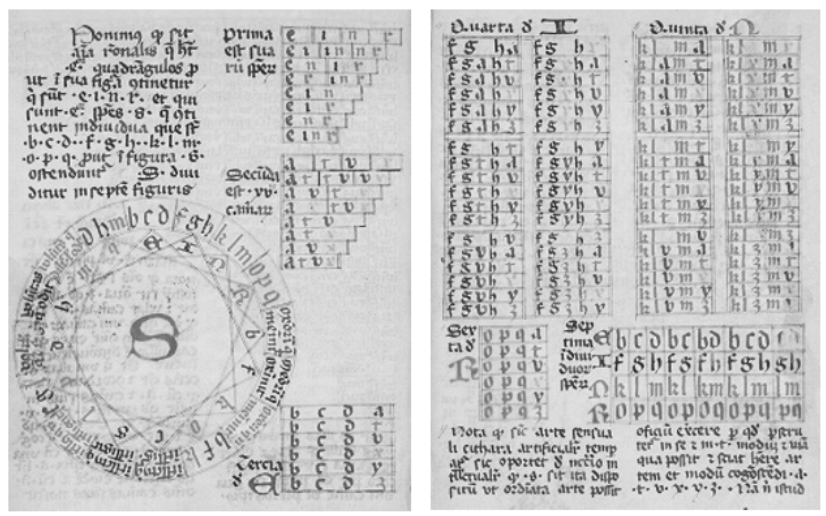

Els diagrames de l'Ars compendiosa inveniendi veritatem. exterior és fix i els dos interiors poden girar, de manera que, per a cada lletra del cercle exterior, es poden produir 28 combinacions de 2 lletres de les altres 8 lletres de I'Alfabet. Com que cada posició permet llegir 9 cambres, el total de combinacions possibles seria $28 \times 9=252$. Llull, però, elimina les repeticions, de manera que només empra la tercera part de les combinacions, és a dir $84.1^{19} \mathrm{La}$ combinatòria lulliana pròpiament dita es desenvolupa a partir de les Figures Tercera i Quarta de l'Ars generalis ultima / Ars brevis (Bonner 2012: 159-174).

Un altre cas de sorprenent intuïció matemàtica és el de la teoria de la votació que Llull presenta al capítol 24 del Romanç d'Evast e Blaquerna, quan explica el càlcul combinatori que permet de trobar la millor candidata per exercir d'abadessa d'un monestir: en la ficció el proposa la monja Natana, que és lectora de l'Art Abreujada d'atrobar veritat. El procediment combinatori no pertany, tanmateix, a la ficció perquè Llull el va reprendre als breus tractats Artificium electionis personarum, del 1274-1283, i De arte electionis, del 1299, que corresponen a reelaboracions de la proposta adequades a les formulacions de l'Art vigents en el moment de la redacció (Hägele \& Pukelsheim 2001). Llull surt al pas d'un problema pràctic: el que tenien plantejat les nombroses comunitats masculines i femenines de l'Església medieval a l'hora de renovar els càrrecs. El sistema de votació de Llull, a mig camí entre la democràcia i la recerca del candidat objectivament més qualificat, proposa l'anàlisi d'un cert nombre de combinacions binàries entre els vots d'un reduit grup de compromissaris prèviament escollits.

19 OS I: 545, 555 i Colomer (1997: 92-108). El desplegament de totes les cambres de les 84 columnes de combinacions dona 1.680 cambres, però Llull només desenvolupa aquesta possibilitat a la Taula general. Les taules de l'Ars generalis ultima i de l'Ars brevis tan sols prenen en consideració 7 columnes de les 84 possibles. 
Els procediments d'elecció lullians són el precedent indiscutible d'una branca de la matemàtica aplicada moderna, la teoria de la votació, que es va començar a formular a França al temps de la Revolució i que no ha estat desenvolupada del tot fins a la dècada dels quaranta del segle passat. McLean i London observen que la presentació formalitzada del mètode lullià de votació al De arte electionis, que és molt semblant al proposat per Condorcet el 1785 , respon a un arranjament lògic conegut com a mitja matriu d'adjacència dintre de la teoria dels grafs (McLean \& London 1992; Bonner \& Bujosa 2006: 88). Les mitges matrius d'adjacència en qüestió són un recurs diagramàtic recurrent en les diverses versions de l'Art.

Anthony Bonner i Albert Soler van dur a terme l'estudi codicològic del manuscrit més antic de l'Ars compendiosa inveniendi veritatem, el Vat. Lat. 5112, que és la versió de l'Art que Llull va escriure immediatament després de la illuminació de Randa el 1274 (Bonner \& Soler 2007). La mise en texte d'aquest manuscrit indica que Llull expressa el seu sistema per primer cop a través de diagrames circulars i tabulars. Aquests diagrames són el que ell anomena les figures de l'Art i constitueixen la part fonamental del manuscrit Vat. Lat. 5112, mentre que les explicacions en prosa el text pròpiament dit- estan presentades com una glossa afegida.

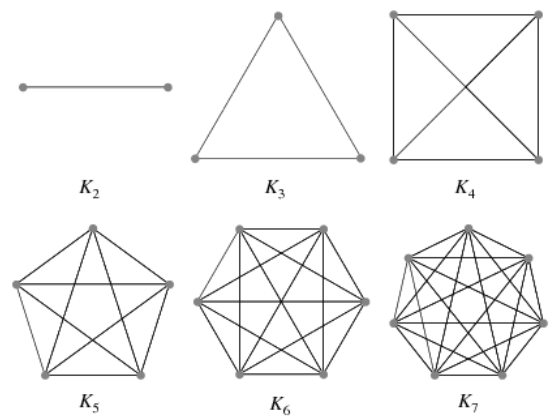

Grafs de 2, 3,4, 5, 6 i 7 vèrtexs amb totes les arestes possibles. Els de Llull són de 16 vèrtexs.

Nou anys més tard, Llull va decidir d'integrar el seu sistema en un discurs lineal al marge dels diagrames. A la ficció del Romanç d'Evast e Blaquerna la monja Natana entenia sense problemes l'Art abreujada d'atrobar veritat i l'aplicava correctament a totes les circumstàncies de la vida,

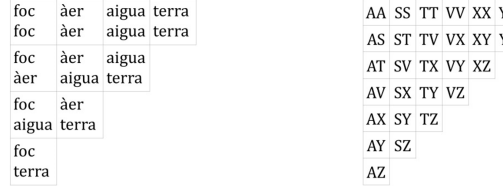

Mitges matrius de la Segona Figura Elemental i de la Figura Demostrativa de l'Art Demostrativa, dibuixades a Bonner \& Soler (2015: 22).

però els lectors formats a la universitat medieval devien trobar molt estranya la presentació diagramàtica d'un sistema de pensament, que, de fet, és un cas únic al segle XIII. A I'Art demostrativa, que és la versió més completa de la primera fase de l'Art, la fase dita quaternària, les figures passen a ser una mena de complement gràfic d'un llibre que es presenta en un format més estàndard, el format convencional que Llull manté en totes les versions successives fins a l'Ars generalis ultima.

Anthony Bonner ha identificat i descrit l'ús d'organitzacions relacionals en forma de graf a les Arts lullianes de la primera fase al seu The Art and Logic of Ramon Llul. A User's Guide / L'Art i la lògica de Ramon Llull. Manual d'ús (Bonner 2012). No hi ha dubte que la intuiició matemàtica de Llull és al cor de «la forma i la manera» que, com explica ell mateix a la Vida de mestre Ramon, va rebre per illuminació a Randa per tal de fer el seu «llibre contra els errors dels infidels» (VMR: 53). Els grafs mostren relacions entre parelles d'objectes o conceptes com les que s'estableixen entre els vèrtexs interconnectats per arestes, inscrits en les figures circulars A, T, V i X de l'Art demostrativa. Llull també va trobar la manera de representar relacions binàries en versió tabular: són les que anomena segones figures, formades per uns triangles de caselles, que són les mitges matrius d’adjacència de la moderna teoria dels grafs, una teoria que va ser posada en circulació per primer cop per Leonard Euler el $1736 .^{20}$

Estirant el fil de la naturalesa i la funció de les figures en les Arts de Llull, Anthony Bonner i Albert Soler han localitzat dues noves mostres d'intuiició matemàtica en el nucli dur del sistema lullià: la teoria dels grafs s'amplia amb la dels hipergrafs i la dels

20 Basart (1994) forneix una visió de conjunt de la teoria que va donar a conèixer per primer cop Leonard Euler proposant una solució general al problema de si es poden travessar els set ponts de Königsberg sense repetir-ne cap en l'intent. 
reticles (Bonner \& Soler 2015: 9-18). La teoria dels hipergrafs és un camp iniciat per Claude Berge el 1970 que va més enllà de la teoria dels grafs, que treballa amb connexions binàries, proposant la representació de connexions entre més de dos elements. ${ }^{21}$ Llull introdueix els hipergrafs a partir de les Arts de l'etapa ternària i afronta la dificultat de donar una representació en dues dimensions dels seus hipergrafs amb el recurs de les rodes giratòries, és a dir les que tenen al seu interior diversos cercles concèntrics que es poden moure produint combinacions de tres o més elements. D'aquestes rodes giratòries, que als estudis diagramàtics s'anomenen volvelles, Llull només en va construir dues: la Figura Demostrativa de l'Art demostrativa, que no acaba encara de desenvolupar el mecanisme complet de l'hipergraf, i la Quarta Figura de les Arts de la segona fase. No tots els hipergrafs lullians es representen en volvelles; per exemple, la Figura $S$ de l'Art demostrativa, que relaciona les potències de l'ànima, enteniment, memòria i voluntat, en l'acte del coneixement, és un hipergraf de base quatre sense aparat giratori.

21 Vegeu Bonner \& Soler (2015), que treballen amb Allwein \& Barwise (1996), Berge (1970) i Birkhoff (1967).
La Figura Elemental de les Arts de la primera fase també és un hipergraf, però Llull la resol aplicant una altra intuïció representativa, que modernament s'ha desenvolupat a través de la teoria dels reticles, la Lattice Theory de Garrett Birkhoff, presentada per primer cop el $1967 \mathrm{com}$ una expansió de la teoria matemàtica de conjunts. Ja s'ha comentat més amunt la dimensió matemàtica de les representacions lullianes de la Figura Elemental present als Començaments de medicina i a l'Art demostrativa (Bonner \& Soler 2015: 18-21).

Bonner i Soler observen que l'ús que fa Llull de la teoria dels reticles requereix una recerca més aprofundida i que també s'ha de valorar el vessant matemàtic de les representacions en forma d'arbre de les Arts, com ara les de l'Arbre de ciència; de tota manera la funció estructuradora dels grafs, dels hipergrafs i dels reticles en la plasmació del sistema de Llull permet de definir les figures de l'Art com un exemple del que, en la moderna ciència, la tecnologia o l'administració d'empreses, s'anomena raonament diagramàtic.

\section{Bibliografia citada}

Abreviatures

AVOMO: Arnaldi de Villanova Opera Medica Omnia, UB (1974-).

MOG: Beati Raymundi Lulli Opera, 10 vols., Magúncia: Häffner, 1721-1740. [Reimpressió: Frankfurt: Minerva Verlag, 1965].

NEORL: Nova Edició de les Obres de Ramon Llull. Palma: Patronat Ramon Llull (1990-).

OE: Ramon Llull, Obres essencials, 2 vols., ed. Joaquim Carreras i Artau Miquel Batllori; Tomàs Carreras i Artau; Jordi Rubió i Balaguer et alii. Barcelona: Selecta, 1957-1960.

OS: RAMON LLULL, Obres selectes, 2 vols. ed. Antoni Bonner, Palma: Moll, 1989. [Original: Selected Works of Ramon Llull, Princeton UP, 1985].

ROL: Raimundi Lulli Opera Latina (I-V, Palma: Maioricensis Schola Lullistica-Consejo Superior de Investigaciones Científicas). A partir de VI (1975), Corpus
Christinanorum. Continuatio Medievalis, Turnhout: Brepols. ROL SL: Raimundi Lulli Opera Latina. Subsidia Lulliana. Dins Corpus Christinanorum. Continuatio Medievalis, Turnhout: Brepols.

TORL: Traducció de l'Obra Llatina de Ramon Llull, Turnhout-Santa Coloma de Queralt: BrepolsObrador Edèndum (2006-)

\section{Obres de Llull citades}

AB: Ars brevis, OS I, 525-595.

AC: Arbre de ciència, OE I, 547-1046.

ACIV: Ars compendiosa inveniendi veritatem I Art abreujada d'atrobar veritat, MOG I 1721, Int. vii, 1-41 (433-473).

ACM: Ars compendiosa medicinae, Mallorca: Pere Antoni Capó, 1752

AE: De arte electionis, SL 41, 2001, 16-20. AEP: Artificium electionis personarum, SL 41, 2001, 7-11.
AGU: Ars generalis ultima, $\mathrm{ROL}$ 14, 1986 (CCCM 75).

AD: Art demostrativa, OS 1, 273-519.

CM: Començaments de medicina, NEORL 4, 2002, 1-12O.

DP: Doctrina pueril, NEORL VII, 2005.

LCD: Llibre de contemplació en Déu, (selecció) ed. Josep Enric Rubio, Barcelona: Barcino, 2009.

LM: Llibre de meravelles, ed. Anthony Bonner, Barcelona-Palma: BarcinoUIB, 2017; NEORL X i XIII, 2011-2014.

LN: Logica nova, NEORL IV, 1998.

LPE: De levitate et ponderositate elementorum, $\mathrm{ROL}$ XXXIV. 2011 (CCCM 246), 151-347.

LRSI: Liber de regionibus sanitatis et infirmitatis, ROL XX, 1995 (CCCM 113), 63-118.

REB: Romanç d'Evast e Blaquerna, ed. Albert Soler i Joan Santanach, Barcelona-Palma: Barcino-UIB, 2016; NEORL VIII, 2009. 
RN: Retòrica nova TORL 1, 2006.

TA: Tractat d'astronomia, NEORL V, 2002, 123-371. Tractatus novus de astronomia ROL XVII, 1989.

VMR: Vida de mestre Ramon, ed. Anthony Bonner, Barcelona-Palma: Barcino-UIB, 2013.

\section{Estudis}

Alberni, Anna, Lola Badia, Lluís Cifuentes \& Alexander Fidora, (eds.), 2012: El saber i les llengües vernacles a l'època de Llull i Eiximenis: estudis ICREA sobre vernacularització $=$ Knowledge and Vernacular Languages in the Age of Llull and Eiximenis: ICREA Studies on Vernacularization, Barcelona: PAM.

Allwein, Gerard \& Jon BARWISE (eds.), 1996: Logical Reasoning with Diagrams, Oxford University Press.

BADIA, Lola, 2000: «Ramon Llull y la cuadratura del círculo», Boletín informativo del Concentus libri, 12, 300-305.

BADIA, Lola, 2002: «The Arbor Scientiæ: A 'New' Encyclopedia in the Thirteenth-Century OccitanCatalan Cultural Context», dins Domínguez, Villalba \& Walter, 1-19.

BADIA, Lola, 2004: «La ciència a l'obra de Ramon Llull»», dins VERNET \& PARÉS, 403-442.

BADIA Lola, Joan SANTANACH \& Albert SOLER, 2013: «Ramon Llull», Història de la Literatura Catalana. Literatura medieval (I). Dels orígens al segle XIV, Barcelona: Enciclopèdia CatalanaBarcino-Aj. de Barcelona, 377-476.

BADIA, Lola, Joan SANTANACH \& Albert SOLER, 2016: Ramon Llull as a Vernacular Writer: Communicating a New Kind of Knowledge, tr. Robert D. Hughes, Londres: Tamesis.

BASART I MUÑoz, Josep M., 1994: Grafs: fonaments i algorismes, Bellaterra: $U A B$.

Berge, Claude, 1970: Graphes et hypergraphes, París: Dunod.

BIRKHOFF, Garrett, 1967: Lattice Theory, Providence Rl: American Mathematical Society Colloquium Publications, 1967; 3 a ed. 1993 i 1995.

BONNER, Anthony, 2002: «The Structure of the Arbor scientiæ», dins DOMÍNGUEZ, VILLALBA \& WALTER, 21-34.
BONNER, Anthony, 2012: L'Art i la lògica de Ramon Llull. Manual d'ús, Barcelona-Palma: UB-UIB.

Bonner, Anthony \& Francesc BujosA, (dirs.), 2006: Història de la ciència a les Illes Balears. Volum I, L'Edat Mitjana, Palma: Govern de les Illes Balears, Conselleria d'Economia, Ciència i Innovació.

BONNER, Anthony \& M. Isabel RIPOLL, 2002: Diccionari de definicions lullianes I Dictionary of Lullian Definitions, Barcelona-Palma: UB-UIB

BONNER, Anthony \& Albert SOLER, 2007: «La mise en texte de la primera versió de l'Art: noves formes per a nous continguts»), Studia Lulliana, 47, 29-50.

BONNER, Anthony \& Albert SOLeR, 2015: «Les figures lullianes: la seva naturalesa i la seva funció com a raonament diagramàtic», Studia Lulliana, 55, 3-30.

Carreras I Artau, Tomás i Joaquín, 2001: Historia de la filosofia espanyola. Filosofia cristiana del segle XIII al XV. Edició facsímil, 2 vols., BarcelonaGirona: IEC-Diputació de Girona, 2001 [Facsímil de l'edició Madrid: Asociación Española para el Progreso de las Ciencias, 19391943].

Cifuentes, Lluís, 2006: La ciència en català a l'Edat Mitjana i el Renaixement. Barcelona-Palma: UB-UIB.

Colomer, Eusebi, 1997: El pensament als Països Catalans durant l'Edat Mitjana i el Renaixment, Barcelona: IEC-PAM.

Domínguez, Fernando, Pere VILLALBA \& Peter WALTeR, (eds.), 2002: Arbor Scientiae: der Baum des Wissens von Ramon Lull. Akten des Internationalen Kongresses aus Anlass des 40-jährigen Jubiläums des Raimundus-Lullus-Instituts der Universität Freiburg i. Br., ROL SL 1.

FIDORA, Alexander \& Josep Enric RUBIO (eds.), 2008: Raimundus Lullus. An Introduction to his Life, Works and Thought, tr. Robert D. Hughes, Anna A. Akasoy i Magnus Ryan, ROL SL 2.

GAYÀ, Jordi, 1980: «Sobre algunes estructures literàries del Libre de Meravelles», Randa, 10, 63-69.

GISBERT, Eugènia, 2004: «Metaforice loquendo: de l'analogia a la metàfora en els Començaments de medicina de Ramon Llull»», Studia Lulliana, 44, 17-52.
HäGELE, Günter \& Friedrich PukELSHeIM, 2001: «Llull's writings on electoral systems», SL, 41, 3-38.

LEIBNIZ, Gottfried Wilhelm, 1666: Dissertatio de arte combinatoria, Leipzig.

Maróstica, A. H., 1992: «Ars Combinatoria and Time: Llull, Leibniz and Peirce», Studia Lulliana, 32, 105-134.

MCLEAN lan \& John LONDON, 1992: «Ramon Lull and the Theory of Voting», Studia Lulliana, 32, 21-37.

Pereira, Michela, 1976: «Ricerche intorno al Tractatus novus de astronomia di Raimondo Lullo», Rivista di storia della filosofia medievale, 2, 169-226.

PereIRA, Michela, 1979: «Le opere mediche di Lullo in rapporto con la sua filosofia naturale e con la medicina del XIII secolo», Estudios Lulianos, 23, 1-35.

PereirA, Michela, 2012: «Ramon Llull e la filosofia in volgare», dins ALBERNI, BADIA, Cifuentes \& FidORA, 2012, 21-44

PISTOLESI, Elena, 2013: «La grammatica lulliana dal trivium all'Arte», Quaderns d'Italià, 18, 45-64.

PRING-MILL, Robert, 1991: Estudis sobre Ramon Llull (1956-1978), Barcelona: PAM.

RUBIO, Josep Enric, 1997: Les bases del pensament de Ramon Llull, ValènciaBarcelona: Institut Interuniversitari de Filologia Catalana-PAM.

RuIz SIMON, Josep Maria, 1999: Ramon Llull i la teoria escolàstica de la ciència Barcelona: Quaderns Crema.

VERNET, Joan \& Ramon PARÉs, (dirs.), 2004: La Ciència en la Història dels Països Catalans. I. Dels àrabs al renaixement, Barcelona-València: IEC-UV.

VICENS, Francesc 2015: «Ramon Llull i la música. L'aportació del doctor illuminat a la literatura medieval musical», Mot so razo, 14, 73-82.

\section{Recursos electrònics}

LlullDB: Base de dades Ramon Llull, Centre de Documentacio Ramon Llull, Universitat de Barcelona <http://orbita.bib.ub.edu/llull>

Sciència.cat: La ciència en la cultura de l'Edat Mitjana i el Renaixement, Universitat de Barcelona <http:// sciencia.cat/> 